\title{
Synthesis of Copper Nanocatalysts with Tunable Size Using Diblock Copolymer Solution Micelles
}

\author{
Yang Liu, Chai Lor, ${ }^{\dagger}$ Qiang Fu, ${ }^{\dagger}$ David Pan, ${ }^{\dagger}$ Lei Ding, Jie Liu, ${ }^{\dagger}$ and Jennifer Lu* ${ }^{*} \dagger$ \\ School of Engineering, University of California, Merced, Merced, California 95348, and Department of \\ Chemistry, Duke University, Durham, North Carolina 27708
}

Received: October 16, 2009; Revised Manuscript Received: February 18, 2010

\begin{abstract}
Self-assembled solution micelles prepared from polystyrene- $b$-poly(4-vinylpyridine) (PS- $b$-P4VP) and polystyrene- $b$-poly(2-vinylpyridine) (PS- $b$-P2VP), have been employed as templates to synthesize copper nanocatalysts which are regarded as an excellent catalyst system for 1D nanomaterial synthesis. We have demonstrated that uniform-sized nanoparticles with diameters ranging from 1 to $15 \mathrm{~nm}$ have been generated. We have revealed that nanocatalyst size can be rationally tailored by adjusting the interaction between copper precursors and ligands and metal sequestration time. Ordered arrays of copper nanocatalysts derived from depositing a monolayer of solution micelles exhibit excellent thermal stability and do not agglomerate during the thermal treatment at $850{ }^{\circ} \mathrm{C}$, typical growth temperature for 1D nanomaterial using the chemical vapor deposition technique. High-density and aligned single-walled carbon nanotubes with uniform diameter have been synthesized using the chemical vapor deposition technique. The average diameter is $1.4 \mathrm{~nm}$, which is on the same order of catalyst size, around $2.0 \mathrm{~nm}$. The combination of tunable size and spacing with superb thermal stability and outstanding catalytic activity offered by this new copper nanocatalyst system will enable growth of high-yield 1D nanomaterials with controllable diameter and spacing consistently and reproducible properties. It also paves a new path to study the effect of nanocatalyst size on $1 \mathrm{D}$ nanomaterial synthesis and their properties.
\end{abstract}

\section{Introduction}

Copper nanoparticles are of great interest in a broad technological arena including catalysis and energy conversion. ${ }^{1-5}$ In particular, copper nanoparticles have shown excellent catalytic capability to synthesize a variety of 1D nanomaterials using chemical vapor based techniques. Copper nanoparticles can catalyze single-walled carbon nanotube (SWNT) growth. ${ }^{3}$ It has been shown that high-density aligned SWNT arrays with over 95\% semiconducting nanotubes have been synthesized using copper nanoparticles. ${ }^{3 a}$ Unlike VIIIA transition metals such as iron, cobalt, and nickel, copper has weak interaction with silicon oxide substrate thus facilitates to the formation of aligned tubes. ${ }^{3 b}$ In addition, the use of copper enables the study of the intrinsic magnetic property of carbon nanotubes. Copper nanoparticles have been proven to be an excellent catalyst system to catalyze $\mathrm{ZnO}$ nanowire growth. ${ }^{4}$ Well-aligned and vertically grown $\mathrm{ZnO}$ nanowires have been generated using a copperbased catalyst system. It is believed that copper can promote the epitaxial growth of $\mathrm{ZnO}$ nanowires. ${ }^{4 \mathrm{a}, \mathrm{b}}$ Copper nanoparticles can catalyze silicon nanowire growth as well. High-purity silicon nanowires with enhanced electron transport property have been synthesized recently. ${ }^{5 a}$ Gold has been widely used for nanowire growth. However gold, a deep-level trap ${ }^{6 a}$ with gold-silicon eutectic temperature of $370{ }^{\circ} \mathrm{C}$, can easily diffuse into the silicon-based active device region during device fabrication. Thus gold is not compatible with Si-based device fabrication. ${ }^{6 \mathrm{~b}, \mathrm{c}}$ Unlike gold, copper, which will not form any compounds with silicon below $800{ }^{\circ} \mathrm{C},{ }^{6 \mathrm{~d}}$ is being extensively used in semiconductor device fabrication. ${ }^{5 c}$

* To whom correspondence should be addressed, jlu5@ucmerced.edu.

${ }^{\dagger}$ University of California, Merced.

* Duke University.
In the chemical vapor deposition (CVD) techniques, catalyst species enable selective adsorption of precursor molecules, facilitate precursor molecule decomposition, and initiate and maintain the growth of nanotubes and nanowires. ${ }^{7-9}$ Therefore, the properties of a 1D nanomaterial dictated by diameter is controlled largely by nanocatalyst size. ${ }^{10,11}$ Two critical growth parameters, local precursor vapor concentration per catalyst species and catalyst activity, are very sensitive to catalyst size. When the growth condition is reached and if all nanocatalysts are similar in size, they all can initiate the growth at the same time leading to high growth yield. Needless to say, the prerequisite for achieving controllable synthesis in high yield is to establish a methodology of synthesizing nanocatalysts with uniform and tunable size.

Several methods have been developed to make copper nanoparticles, including laser ablation ${ }^{12}$ and wet chemical reactions. $^{1,2}$ These methods can produce nanoparticles with controlled size in solution. However, there is no means to generate ordered arrays on surfaces, which is essential for substrate-based synthesis of 1D nanomaterials. Ordered nanoparticle arrays can be prepared by either top-down or bottomup approaches. Conventional top-down lithography has successfully pushed the feature size down to the sub-100-nm regime. Alternative methods such as e-beam lithography and nanoimprinting have been able to create features in the sub20 -nm region, ${ }^{14,15}$ but they are limited by high cost and low throughput. On the contrary, the bottom-up approaches can generate sub-20-nm features at low cost and high throughput by building up nanoscale units through controlled assembling and organization of molecules and atoms. ${ }^{16}$

Self-assembled block copolymers have been widely used for nanostructure fabrication. Block copolymers can self-assemble into a wide range of nanoscale morphologies such as spheres, 


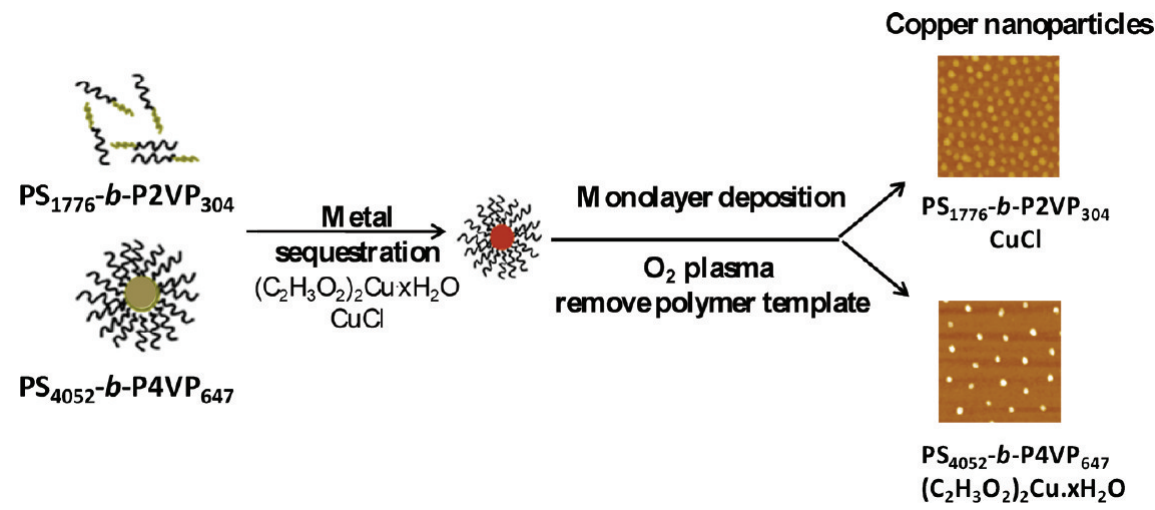

Figure 1. Schematic illustration of generating copper nanocatalyst arrays on surface with self-assembled PS- $b$-PVP diblock copolymers as micelles.

cylinders, and lamellae. One of the applications is to employ spherical micelles as nanoreactors to produce inorganic nanoparticle arrays. For instance, polystyrene-block-poly (4-vinylpyridine) (PS- $b$-P4VP) can selectively localize tetrachloroauric acid on the P4VP blocks by electrostatic interaction, leading to ordered gold nanoparticle arrays. ${ }^{15 b}$ Precursors can also be incorporated into the solution micelle cores via ionic or coordination interactions. The precursor-loaded micelles can then be transferred to substrates. After the removal of polymers, nanocatalyst arrays will be yielded. ${ }^{15 \mathrm{~b}, \mathrm{~d}, \mathrm{e}}$

In this paper, a systematic investigation was conducted to explore the use of solution templates generated by PS- $b$-P4VP and polystyrene- $b$-poly(2-vinylpyridine) (PS- $b$-P2VP) to synthesize copper nanocatalysts. According to the kinetic study, P4VP molecules of PS- $b$-P4VP can sequester copper species at a higher rate than P2VP molecules of PS- $b$-P2VP. On comparison of copper(I) chloride with copper(II) acetate hydrate, copper(I) chloride can be incorporated at the highest rate, resulting in largest nanocatalysts. There is limited ability for anhydrous copper(II) acetate to be localized by pyridyl groups. The size of nanoparticle can be tailored by the sequestration time. Copper nanocatalyst arrays with size spanning from 1 to $15 \mathrm{~nm}$ have been generated. Unlike other bottom-up techniques, size and spacing between nanoparticles can be adjusted independently. Ordered sub-10-nm copper nanoparticles with spacing around $100 \mathrm{~nm}$ have been achieved using $\mathrm{PS}_{4052}-b-\mathrm{P}_{4} \mathrm{VP}_{647}$.

The copper nanocatalyst arrays synthesized by this approach exhibited excellent thermal stability and catalytic activity and gave rise to high-density aligned single-walled CNTs. The strategy of tailoring the metal sequestration by varying coordination reaction conditions enables the rational control of copper nanocatalyst size and can be extended to the preparation of other transitional metal nanocatalysts. The block copolymer micelle approach, capable of producing copper nanocatalysts with tunable size and spacing, together with excellent catalytic activity and thermal stability, opens a new way to synthesize periodically ordered $1 \mathrm{D}$ nanomaterials with controlled diameter at high yield.

\section{Experimental Section}

1. Copper Nanocatalyst Synthesis. Diblock copolymers polystyrene 422000- $b$-poly (4-vinylpyridine) $68000\left(\mathrm{PS}_{4052}-b\right.$ $\mathrm{P}_{4 \mathrm{VP}_{647}}$ ) and polystyrene $185000-b$-poly(2-vinylpyridine) 32000 $\left(\mathrm{PS}_{1776}-b-\mathrm{P} 2 \mathrm{VP}_{304}\right)$ were purchased from Polymer Source (Quebec, Canada). The copolymers were first dissolved in toluene to form $0.3 \mathrm{wt} \%$ solutions. Copper(I) chloride, copper(II) acetate anhydrate, and copper(II) acetate hydrate were obtained from Sigma-Aldrich (St. Louis, MO). Equimolar amounts of copper precursors were added to the polymer solutions. After being stirred for a certain period of time, the solutions were filtered through $0.2 \mu \mathrm{m}$ PTFE syringe filters. The filtrates were then spin-coated on silicon shards and baked at $100{ }^{\circ} \mathrm{C}$ for 2 $\min$. The films were then subjected to $\mathrm{UV}-$ ozone treatment at $100{ }^{\circ} \mathrm{C}$ for $20 \mathrm{~min}$ to remove organics to form copper nanocatalysts.

2. Catalytic Activity Investigation: Single-Walled CNT Growth. To grow single-walled CNTs, ST-cut single quartz surface (Hoffman Materials Inc.) coated with catalyst arrays patterned using the previously published method were transferred to a $1 \mathrm{in}$. quartz tube sitting in a furnace. ${ }^{3 \mathrm{a}}$ The substrates were first heated up to $600{ }^{\circ} \mathrm{C}$ and annealed in air for $20 \mathrm{~min}$. After the furnace was cooled down to room temperature, the quartz tube was then purged with $200 \mathrm{sccm}$ of argon to remove residual air. The furnace temperature was then raised to $850{ }^{\circ} \mathrm{C}$ under hydrogen. After the furnace reached $850{ }^{\circ} \mathrm{C}$ for another $10 \mathrm{~min}, 200 \mathrm{sccm}$ of ethanol was added to initiate CNT growth on quartz substrates. After $20 \mathrm{~min}$, the ethanol gas flow was switched off and the furnace was cooled down under hydrogen protection.

3. Copper Nanocatalysts and Single-Walled CNT Characterization. Nanoparticles were characterized by atomic force microscopy (AFM, Park System Inc., Santa Clara, CA). X-ray photoelectron spectrometer (XPS, Physical Electronics, Chanhassen, MN) was employed to study their chemical composition and oxidation state. X-ray photoelectron spectra were obtained using a Physical Electronics Quantum 2000 scanning XPS system with a focused monochromatic $\mathrm{Al} \mathrm{K} \alpha \mathrm{X}$-ray source for excitation and a spherical section analyzer. A $1 \mathrm{~mm}$ diameter $\mathrm{X}$-ray beam was used for analysis. The X-ray beam was incident normal to the sample, and the X-ray detector was at $45^{\circ}$ away from the normal. The pass energy was $23.5 \mathrm{eV}$, giving an overall energy resolution of $0.3 \mathrm{eV}$. The collected data were referenced to an energy scale with binding energies for $\mathrm{Cu} 2 \mathrm{p}_{3 / 2}$ at 932.72 $(0.05 \mathrm{eV})$ and $\mathrm{Au} 4 \mathrm{f}_{7 / 2}$ at $84.01(0.05 \mathrm{eV})$.

CNT samples were inspected by scanning electron microscopy (SEM, FEI Co., Hillsboro, OR). AFM and Raman analysis (Renshaw inVia Raman Microscope) were used to estimate CNT diameter. The laser illumination area was $1 \mu \mathrm{m}^{2}$, and wavelength is $514 \mathrm{~nm}$. The integrated time was $20 \mathrm{~ms}$, and the laser power was around $1 \mathrm{~mW}$.

\section{Results and Discussion}

The schematic process flow to prepare nanocatalyst arrays on surfaces is illustrated in Figure 1. A diblock copolymer consists of a hydrophobic PS block and a hydrophilic PVP block. Toluene is a favorable solvent for the PS block but unfavorable for the PVP 

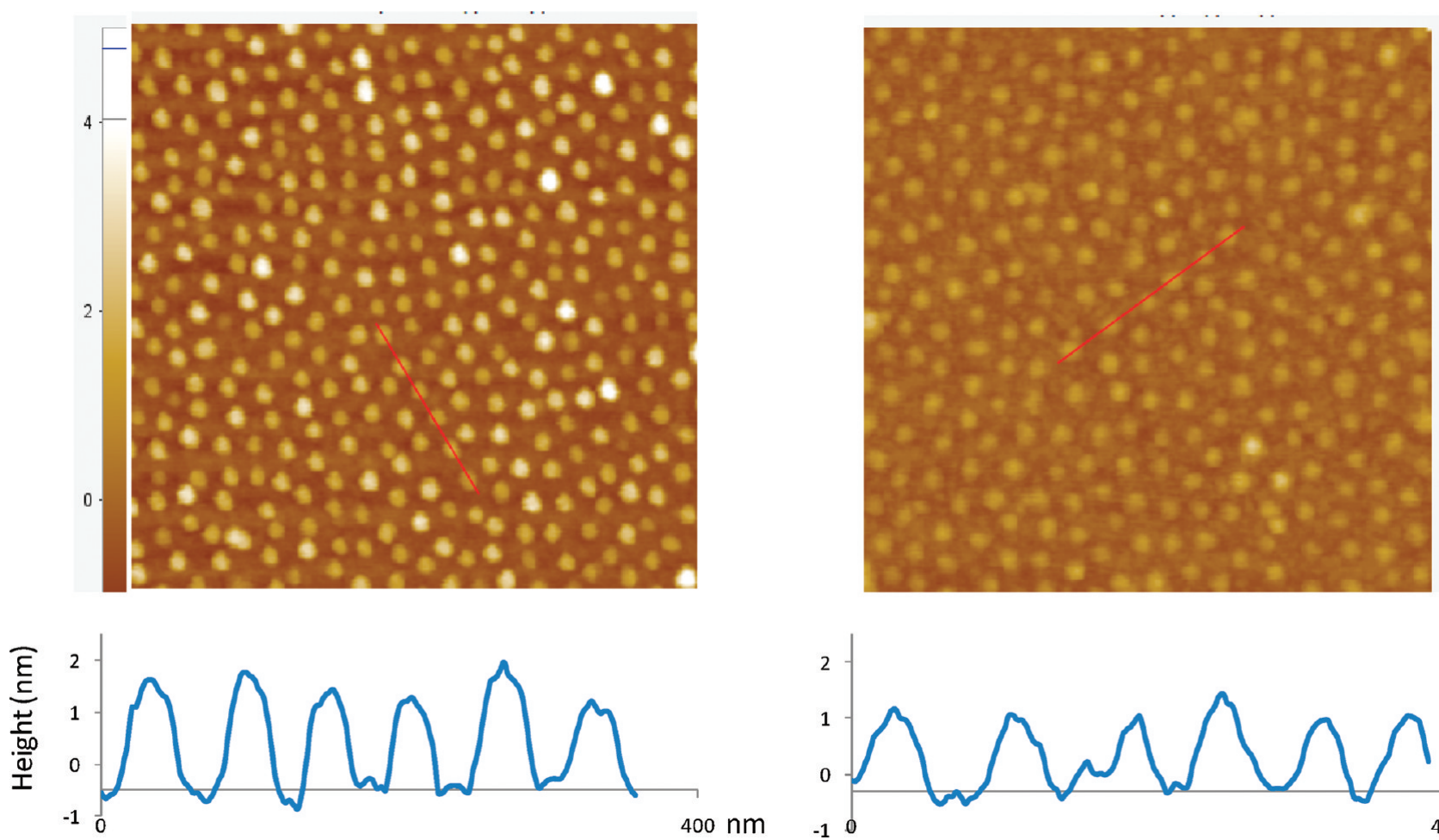

$400 \mathrm{~nm}$

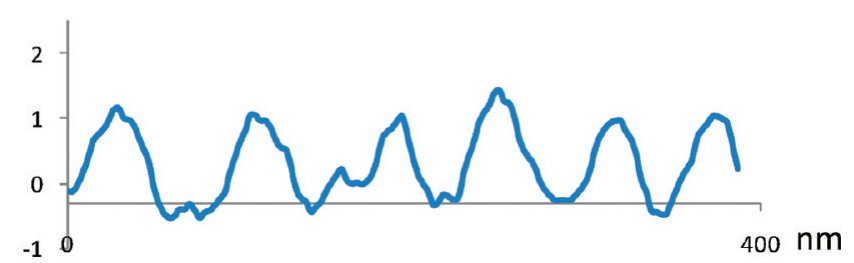

Figure 2. AFM height images (scan area: $1 \mu \mathrm{m}$ by $1 \mu \mathrm{m}$ ) and profiles of copper nanocatalysts prepared from solution micelles of $\mathrm{PS}_{1776}-b$ - $\mathrm{P}_{2} \mathrm{VP}_{304}$ using copper(I) chloride (left) and copper(II) acetate hydrate (right) after $240 \mathrm{~h}$ of reaction time.

block, especially for P4VP. As a result, PS- $b$-P4VP will selfassemble into micelles whose coronas are composed of PS and cores are formed by P4VP. By coordinating copper species with the pyridine groups in the cores, the copper-loaded micelles can be generated. P2VPs are less hydrophilic than P4VP. Thus PS- $b$ P2VP has fewer tendencies to self-assemble in toluene. However, the solubility contrast between PS and P2VP blocks is enhanced after the incorporation of metal species into P2VP blocks, resulting in the formation of copper-containing micelles. After spin-coating solution micelles on a surface, $\mathrm{UV}$ - ozone treatment was used to remove the polymer template, yielding inorganic nanoparticle arrays in hexagonal lattice.

1. Copper Nanocatalyst Formation Using Different Copper Precursors. Selective localization of copper species into PVP cores is essential for the formation of nanoparticles. Copper(I) chloride and copper(II) acetate hydrate were chosen to compare the sequestration ability of $\mathrm{PS}_{1776}-b-\mathrm{P} 2 \mathrm{VP}_{304}$ and $\mathrm{PS}_{4052}-b-\mathrm{P} 4 \mathrm{VP}_{647}$ because of different metal complexation tendency due to the location of nitrogen. ${ }^{17}$ Figure 2 is a set of AFM images of nanoparticles derived from metal-modified $\mathrm{PS}_{1776}-b-\mathrm{P} 2 \mathrm{VP}_{304}$ solution micelles. The average nanocatalyst sizes are 1.9 and $1.1 \mathrm{~nm}$, respectively. Clearly, nanoparticles are arranged in a quasi-hexagonal fashion. Figure 3 is a set of AFM images of nanocatalysts formed using $\mathrm{PS}_{4052}-b-\mathrm{P}_{4} \mathrm{VP}_{647}$ as a template. The average sizes are 13 and $8 \mathrm{~nm}$, respectively, which were much bigger than those prepared using $\mathrm{PS}_{1776}-b$ $\mathrm{P}_{2} \mathrm{VP}_{304}$. Larger particles have been formed using the PS- $b$ $\mathrm{P} 4 \mathrm{VP}$ micelle template since the nitrogen in P4VP is more accessible and exhibits greater propensity to bind metal species. More copper species from copper(I) chloride can be sequestered which can be rationalized by less steric hindrance effect. This size difference indicates that the extent of the coordination reaction can be used to tune particle size.

Furthermore, another salient feature of this approach is that not only the size but also the spacing can be adjusted. Unlike other synthesis methods which have limited capability to tune particle spacing and often yield very densely packed nanoparticles, ${ }^{1,2 \mathrm{c}}$ these high molecular weight polymer systems, $\mathrm{PS}_{1776}-b-\mathrm{P}_{2} \mathrm{VP}_{304}$ and $\mathrm{PS}_{4052}-b-\mathrm{P}_{4} \mathrm{VP}_{647}$, were chosen to demonstrate that relatively large spacing can be created. The average distance between nanoparticles is about $55 \mathrm{~nm}$ for $\mathrm{PS}_{1776}-b-\mathrm{P} 2 \mathrm{VP}_{304}$ while the periodicity is around $100 \mathrm{~nm}$ for $\mathrm{PS}_{4052}-b-\mathrm{P}_{4} \mathrm{VP}_{647}$, bridging nanoscale to microscale.

2. Kinetics of Copper Species Incorporation. A kinetics study of copper incorporation provides insight on the dynamic metal sequestration process. In this experiment, copper-containing polymer solutions were taken out at different time intervals. The size nanocatalyst was estimated by AFM height analysis.

Figure $4 \mathrm{a}$ is a plot of nanocatalyst size vs time. Figure $4 \mathrm{~b}$ is a histogram showing average and standard deviation of copper nanoparticles prepared from $\mathrm{PS}_{4052}-b-\mathrm{P}_{4} \mathrm{VP}_{647}$. Overall nanocatalyst size increases with time, and there is a slight increase in particle size variation with the increase of particle size. The following conclusions can be drawn from this investigation. First of all, the nanocatalyst size increases over time, indicating that more copper species can be incorporated into the polymer copolymer micelles with time. This reaction rate is partially controlled by diffusion. Second, $\mathrm{PS}_{4052}-b-\mathrm{P} 4 \mathrm{VP}_{647}$ can localize more copper species at a higher rate than $\mathrm{PS}_{1776}-b-\mathrm{P} 2 \mathrm{VP}_{304}$. This result manifests that the steric hindrance effect can greatly influence the kinetic and thermodynamic aspect of metal sequestration. Third, comparing copper sequestration rate, copper(I) chloride is the fastest and anhydrous copper(II) acetate is the slowest. Using the same template $\left(\mathrm{PS}_{4052}-b-\mathrm{P} 4 \mathrm{VP}_{647}\right), 15$ $\mathrm{nm}$ copper nanoparticles have been produced using copper(I) chloride while less than $8 \mathrm{~nm}$ copper nanoparticles have been generated using copper(II) acetate anhydrate after the same period of time. It can be deduced that the choice of copper precursor is important. All these findings indicate that the coordinate interaction between metal precursor and their corresponding polymer functional group plays an important role in nanoparticle formation. In the case of $\mathrm{PS}_{1776}-b-\mathrm{P}_{2} \mathrm{VP}_{304}$, 

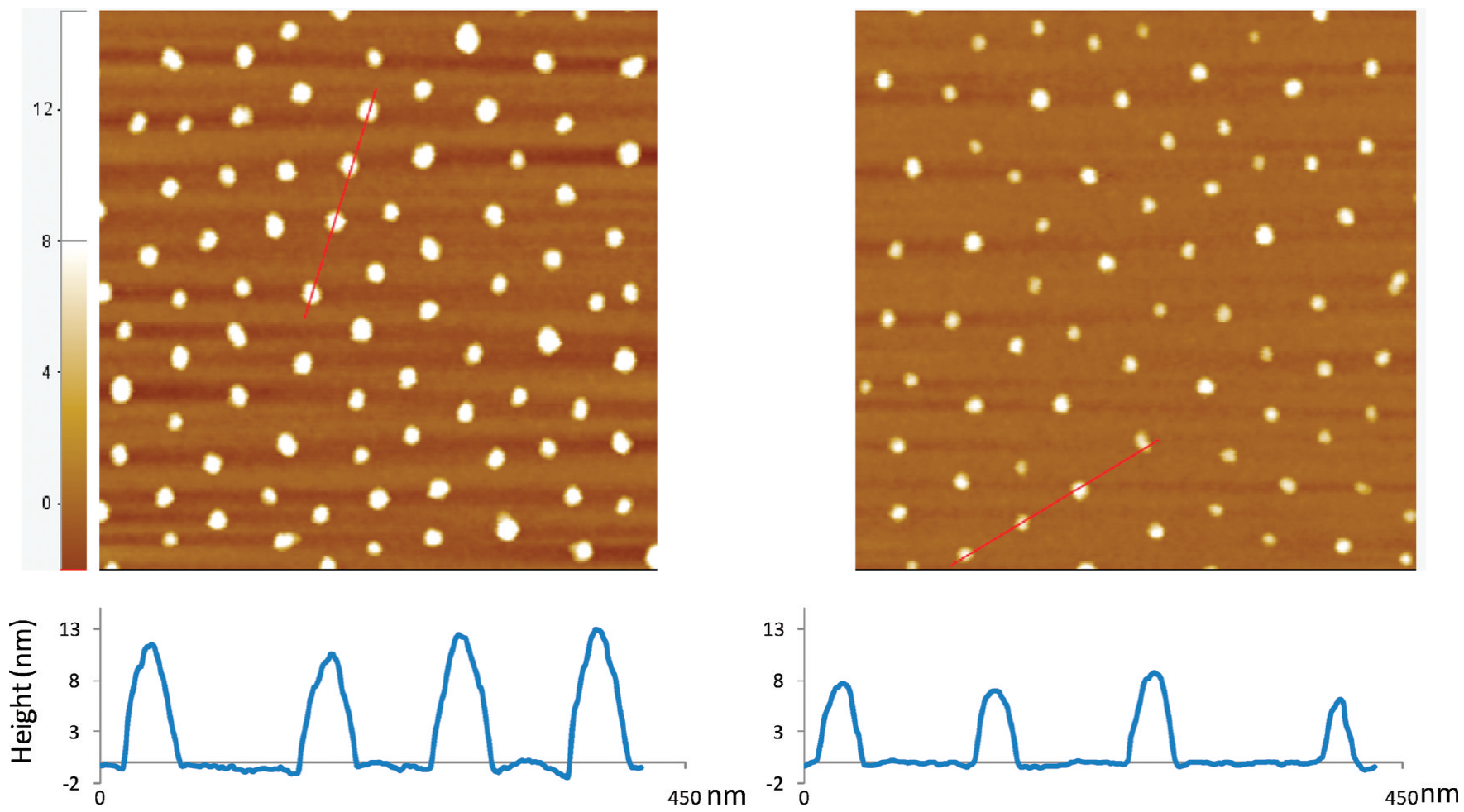

Figure 3. AFM height images (scan area: $1 \mu \mathrm{m}$ by $1 \mu \mathrm{m}$ ) and profiles of copper nanocatalysts prepared from solution micelles of $\mathrm{PS}_{4052}-b$ - $\mathrm{P}_{4 \mathrm{VP}} \mathrm{P}_{647}$ using copper(I) chloride (left) and copper(II) acetate hydrate (right) after $240 \mathrm{~h}$ of reaction time.

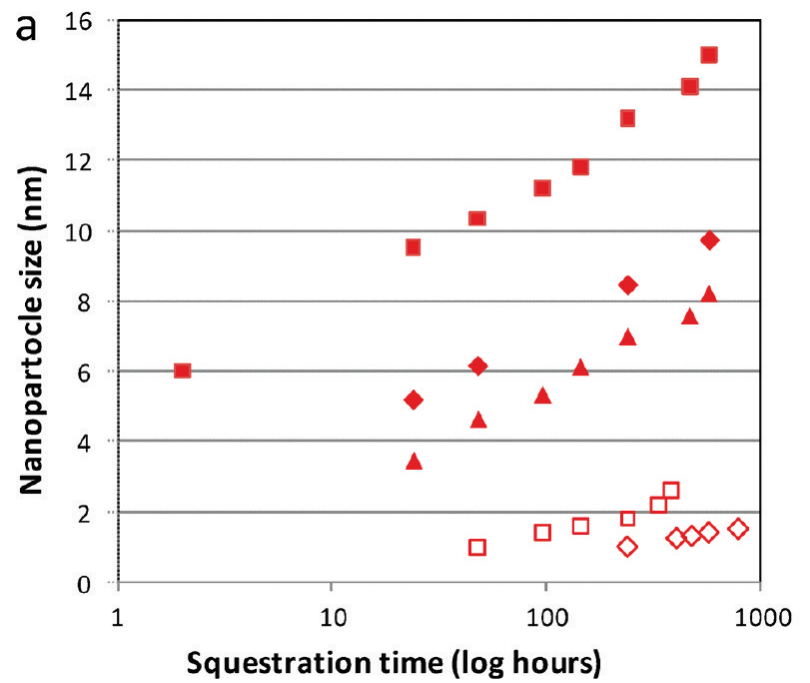

b

$\mathrm{PS}_{4057}-b-P 4 V P_{648}$

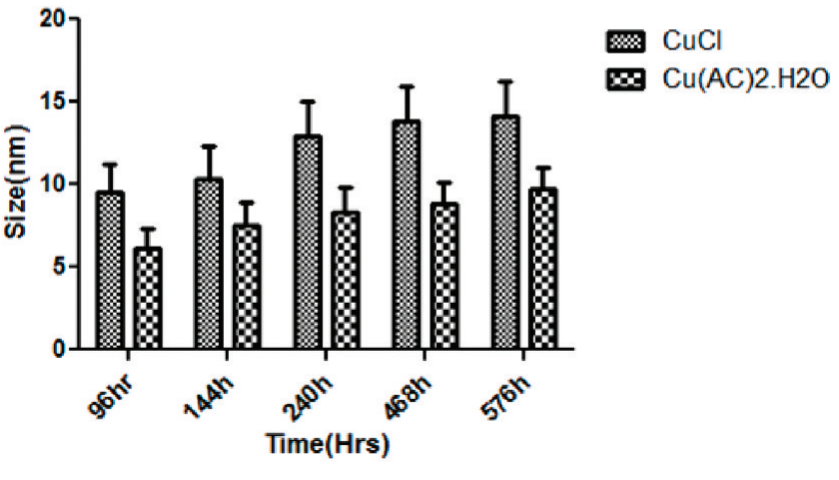

Figure 4. AFM height analysis result: (a) nanoparticle size vs reaction time; (b) Histogram showing the change of nanoparticle average size and standard deviation of average with time.

nanocatalysts can only be observed after $240 \mathrm{~h}$ with copper(II) acetate hydrate and no nanoparticles can be detected with copper(II) acetate anhydrate. On the contrary, 8-9 nm nanocatalysts have been observed after $10 \mathrm{~h}$ in the system of $\mathrm{PS}_{4052^{-}}$ $b$-P4VP 647 with copper(I) chloride. Hence, tailoring the extent of metal coordination reaction can be used to adjust nanoparticle size.

3. Chemical Analysis of Nanoparticles. XPS was used to determine chemical composition and state of resultant nanoparticles on surfaces after UV-ozone treatment. Figure 5 is a XPS spectrum of nanoparticles prepared using $\mathrm{PS}_{4052}-b-\mathrm{P}_{4} \mathrm{VP}_{647}$ and copper(I) chloride. The binding energy peaks indicate that as-synthesized nanoparticles are copper(I) oxide. ${ }^{17}$

4. Thermal Stability. Because elevated temperature is used for growing 1D nanomaterial using the CVD process

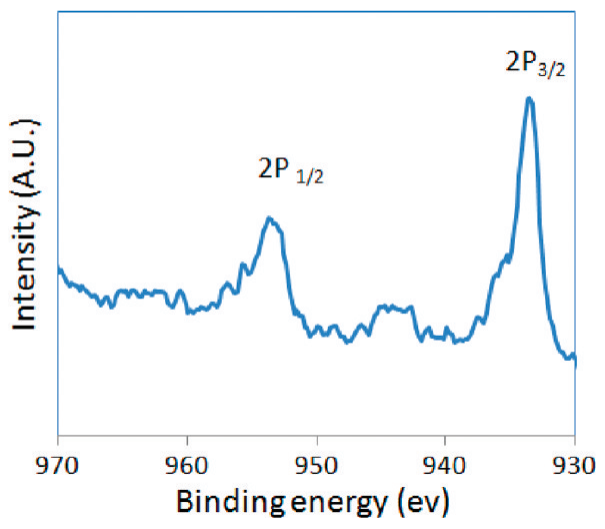

Figure 5. XPS spectrum of as-synthesized nanoparticles derived from copper(I) chloride and $\mathrm{PS}_{4052}-b$-P4VP 647 after $\mathrm{UV}-$ ozone treatment. 

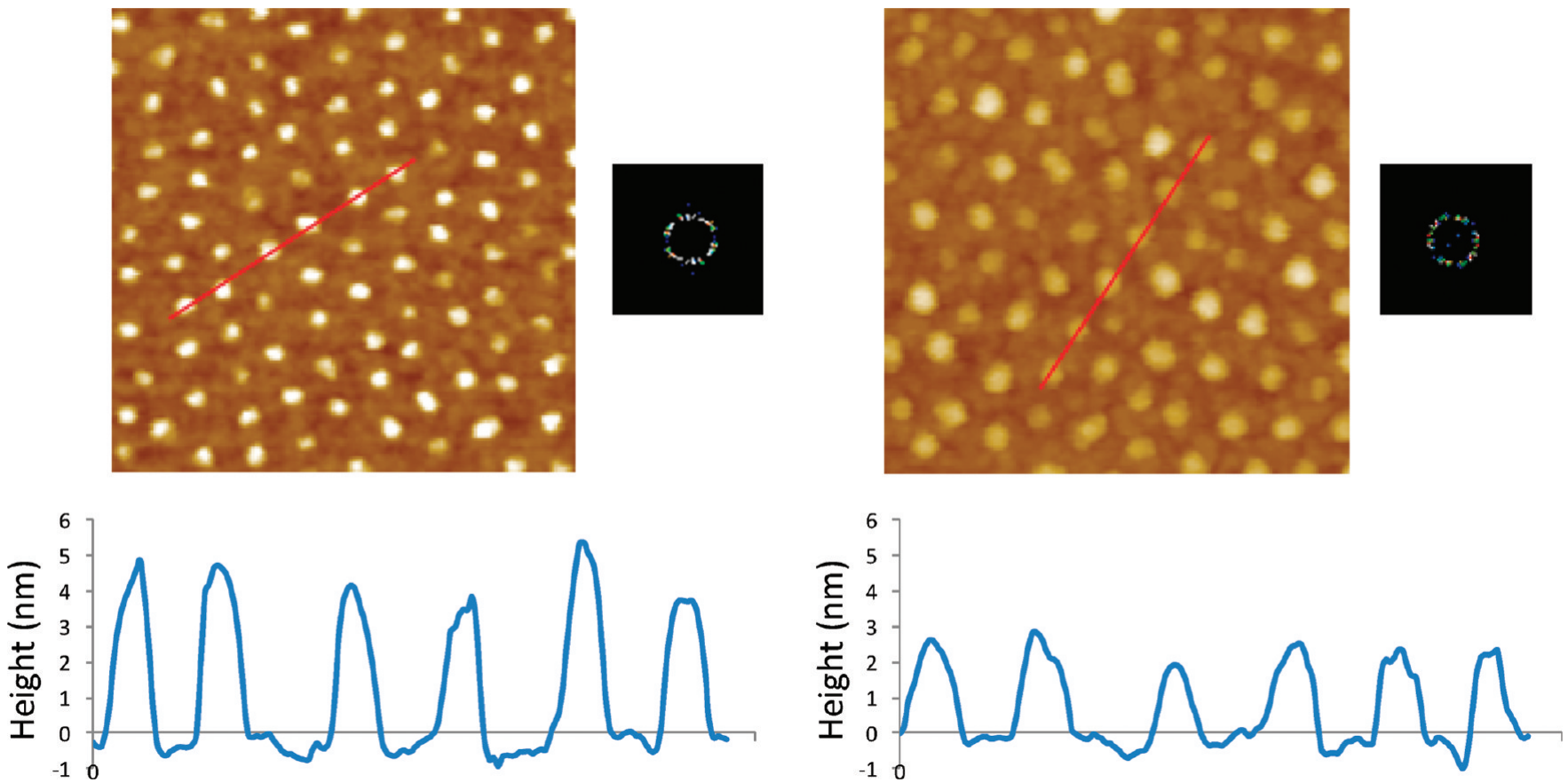

Figure 6. AFM height images (scan area, $0.5 \mu \mathrm{m}$ by $0.5 \mu \mathrm{m}$; height scale, $6.0 \mathrm{~nm}$ ) of copper nanocatalyst arrays before and after annealing at 850 ${ }^{\circ} \mathrm{C}$. The insets are corresponding Fourier transform images.

technique, it is important to study the thermal stability of nanocatalysts at the onset of growth temperature. The copper nanocatalyst arrays were first annealed in air at $600{ }^{\circ} \mathrm{C}$ for 20 min to remove all the organics and also cleanup the surface. Then argon was introduced to remove the air. After 5 min of purging under argon, hydrogen was added. The furnace was finally ramped up to $850{ }^{\circ} \mathrm{C}$ under a mixture of hydrogen and argon, the copper nanocatalyst arrays were soaked at $850{ }^{\circ} \mathrm{C}$ for 5 min before being cooled down to room temperature. This thermal treatment process mimics the CNT growth condition used in this investigation. Figure 6 is a set of AFM height images and associated height profiles of copper nanocatalyst arrays before and after annealing. Although the nanocatalyst size is reduced from 4.5 to 2.5 $\mathrm{nm}$ after the thermal treatment, the quasi-hexagonal order and spacing remained intact as indicated by 2D Fourier

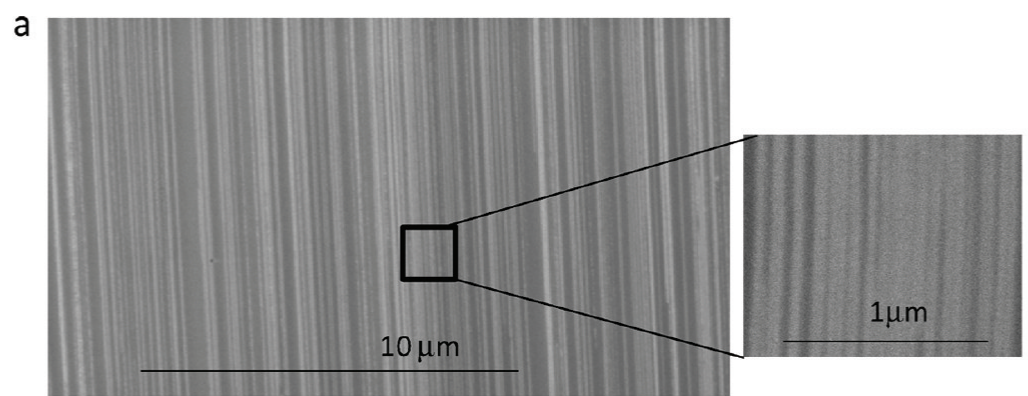

b

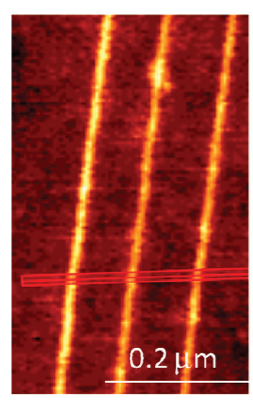

C

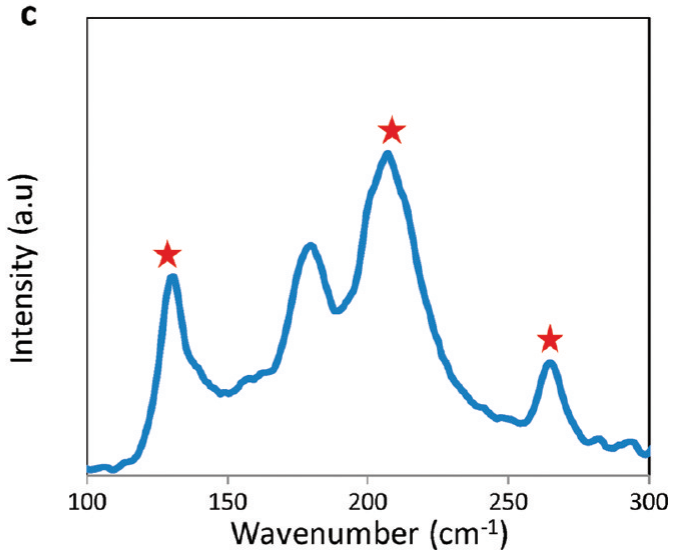

Figure 7. (a) SEM images of the aligned CNTs synthesized using patterned nanocatalyst arrays. (b) Representative AFM height image and profile of CNTs. (c) Radial breathing mode Raman spectra. The sharp peaks at 132 and $265 \mathrm{~cm}^{-1}$ and the broad peaks at $208 \mathrm{~cm}^{-1}$, marked with red stars, correspond to the Raman spectra of the quartz. 
transform analysis. It can be clearly seen that nanoparticles on the surface have not migrated or agglomerated during the thermal treatment, implying that these nanocatalysts are very stable.

5. Catalytic Activity for 1D Nanomaterial Growth-CNT Synthesis. To evaluate the catalytic activity to initiate 1D nanomaterial growth, copper nanocatalyst arrays prepared from copper(I) chloride using $\mathrm{PS}_{4052}-b-\mathrm{P}_{4} \mathrm{VP}_{647}$ as a template was used to grow CNTs on ST-cut single crystal quartz surfaces. The assynthesized nanocatalysts after UV-ozone treatment have an average particle size of $4 \mathrm{~nm}$. At the onset growth temperature, nanoparticle size is $2 \mathrm{~nm}$ with the majority of nanoparticles falling between 1.4 and $2.5 \mathrm{~nm}$. Figure $7 \mathrm{a}$ is a representative scanning electron micrograph image showing high-density aligned CNTs. Densities of 8-15 tubes per micrometer have been achieved with yield about 5-10\%. The reasonably high conversion is a result of uniform sized nanocatalysts. The narrower the size distribution of nanocatalysts, the higher the percentage of nanocatalysts that will participate in CNT growth, leading to high growth yield. Figure $7 \mathrm{~b}$ is a representative AFM height image and responding profile showing that CNTs have uniform diameter, the majority of tubes with $1.2-1.4 \mathrm{~nm}$. This result is in good agreement with the Raman analysis at the radial breathing mode with the peak corresponding to $1.4 \mathrm{~nm}$, displayed in Figure 7c. As predicted from the so-called Kataura plot, this is a semiconducting nanotube. Since an appropriate local vapor precursor concentration is required to initiate CNT growth, catalysts that are too small or too large will not grow CNTs. This might be the reason why the distribution of CNTs is narrower than that of nanocatalysts. Because the diameter of single-walled CNTs is governed by the size of nanocatalysts, ordered nanocatalyst arrays with uniform size not only facilitate high-yield growth and but also promote the diameter control of as-synthesized 1D nanomaterials.

\section{Conclusions}

This is the first systematic investigation of static and dynamic sequestration of metal species into polymer micelle templates. It has been revealed that the extent of metal coordination can be modulated by tuning the interplay between metal precursors and the functional groups composed of micelle cores. Consequently, nanocatalyst size can be rationally adjusted. Comparing copper(I) chloride with copper(II) acetate hydrate and anhydrous copper(II) acetate, the largest nanocatalysts can be generated in the shortest period of time using copper(I) chloride. The kinetic investigation also reveals that copper species can be incorporated in the PS- $b$ $\mathrm{P} 4 \mathrm{VP}$ micelles at a much faster rate than PS- $b$-P2VP micelles. Furthermore, by adjusting the reaction time, nanoparticle size can also be adjusted. This set of new insights of using polymer micelles as nanoscale reactors for nanoparticle synthesis provides a new way to generate tunable and uniform nanocatalysts reproducibly. This methodology can be extended to synthesize other inorganic nanoparticle systems. Copper nanocatalysts synthesized using this approach has been proven to be an effective catalyst system for single-walled CNT growth. Uniform-diameter and high-yield aligned CNTs have been produced. Combining excellent thermal stability with tunable size and spacing offered by nanocatalyst systems prepared by this block copolymer approach will facilitate more controllable synthesis of 1D nanomaterials with location and diameter control and consequently control of properties.

Acknowledgment. This work is supported by the start-up fund at the University of California, Merced, and the NSF-CBET fund. We would like to acknowledge help from C. Nyugen at the NASA Ames for the Raman analysis and Art Nelson at the Physical \& Life Sciences Directorate, Lawrence Livermore National Laboratory.

\section{References and Notes}

(1) (a) Bordiga, S.; Paze, C.; Berlier, G.; Scarano, D.; Spoto, G.; Zecchina, A.; Lamberti, C. Catal. Today 2001, 70 (1-3), 91-105. (b) Dhas, N. A.; Raj, C. P.; Gedanken, A. Chem. Mater. 1998, 10 (5), 1446-1452. (c) Vitulli, G.; Bernini, M.; Bertozzi, S.; Pitzalis, E.; Salvadori, P.; Coluccia, S.; Martra, G. Chem. Mater. 2002, 14 (3), 1183-1186.

(2) (a) de Jongh, P. E.; Vanmaekelbergh, D.; Kelly, J. J. Chem. Commun. 1999, (12), 1069-1070. (b) Poizot, P.; Laruelle, S.; Grugeon, S.; Dupont, L.; Tarascon, J. M. Nature 2000, 407 (6803), 496-499. (c) Yin, M.; Wu, C. K.; Lou, Y. B.; Burda, C.; Koberstein, J. T.; Zhu, Y. M.; O'Brien, S. J. Am. Chem. Soc. 2005, 127 (26), 9506-9511.

(3) (a) Ding, L.; Tselev, A.; Wang, J. Y.; Yuan, D. N.; Chu, H. B.; McNicholas, T. P.; Li, Y.; Liu, J. Nano Lett. 2009, 9 (2), 800-805. (b) Zhou, W. W.; Han, Z. Y.; Wang, J. Y.; Zhang, Y.; Jin, Z.; Sun, X.; Zhang, Y. W.; Yan, C. H.; Li, Y. Nano Lett. 2006, 6 (12), 2987-2990. (c) Takagi, D.; Homma, Y.; Hibino, H.; Suzuki, S.; Kobayashi, Y. Nano Lett. 2006, 6 (12), 2642-2645.

(4) (a) Li, S. Y.; Lee, C. Y.; Tseng, T. Y. J. Cryst. Growth 2003, 247 (3-4), 357-362. (b) Li, S. Y.; Lin, P.; Lee, C. Y.; Tseng, T. Y. J. Appl. Phys. 2004, 95 (7), 3711-3716. (c) Xu, C. X.; Sun, X. W.; Zhang, X. H.; Ke, L.; Chua, S. J. Nanotechnology 2004, 15 (7), 856-861.

(5) (a) Boettcher, S. W.; Spurgeon, J. M.; Putnam, M. C.; Warren, E. L.; Turner-Evans, D. B.; Kelzenberg, M. D.; Maiolo, J. R.; Atwater, H. A.; Lewis, N. S. Science 2010, 327 (5962), 185-187. (b) Kalache, B.; Cabarrocas, P. R.; Morral, A. F. Jpn J. Appl. Phys., Part 2 2006, 45 (4-7), L190L193. (6). (c) Arbiol, J.; Kalache, B.; Cabarrocas, P. R. I.; Morante, J. R.; Morral, A. F. I. Nanotechnology 2007, 18 (30)), (d) Arbiol, J.; Morral, A. F. I.; Estrade, S.; Peiro, F.; Kalache, B.; Cabarrocas, P. R. I.; Morante, J. R. J. Appl. Phys. 2008, 104, 064312.

(6) (a) Morante, J. R.; Carceller, J. E.; Herms, A.; Cartujo, P.; Barbolla, J. Appl. Phys. Lett. 1982, 41 (7), 656-658. (b) Wolf, S.; Tauber, R. N. Silicon Processing for the VLSI Era, 2nd ed.; Lattice Press: Sunset Beach, CA, 2000; p 890. (c) Schmidt, V.; Wittemann, J. V.; Senz, S.; Gosele, U. Adv. Mater. 2009, 21 (25-26), 2681-2702. (d) Baker, H. O., H.; Henry, S. D.; Davidson, G. M.; Fleming, M. A.; Kacprazk, L.; Lampman, H. F. ASM Handbook; ASM International: Materials Park, OH, 1987; Vol. 3.

(7) (a) Colomer, J. F.; Stephan, C.; Lefrant, S.; Van Tendeloo, G.; Willems, I.; Konya, Z.; Fonseca, A.; Laurent, C.; Nagy, J. B. Chem. Phys. Lett. 2000, 317 (1-2), 83-89. (b) Kong, J.; Soh, H. T.; Cassell, A. M.; Quate, C. F.; Dai, H. J. Nature 1998, 395 (6705), 878-881.

(8) (a) Duan, X. F.; Lieber, C. M. Adv. Mater. 2000, 12 (4), 298-302. (b) Huang, M. H.; Wu, Y. Y.; Feick, H.; Tran, N.; Weber, E.; Yang, P. D. Adv. Mater. 2001, 13 (2), 113-116. (c) Morales, A. M.; Lieber, C. M. Science 1998, 279 (5348), 208-211. (d) Wagner, R. S.; Ellis, W. C. Appl. Phys. Lett. 1964, 4 (5), 89-90.

(9) Kolasinski, K. W. Curr. Opin. Solid State Mater. Sci. 2006, 10 (3-4), 182-191.

(10) (a) Cheung, C. L.; Kurtz, A.; Park, H.; Lieber, C. M. J. Phys. Chem. $B$ 2002, 106 (10), 2429-2433. (b) Cui, Y.; Lauhon, L. J.; Gudiksen, M. S.; Wang, J. F.; Lieber, C. M. Appl. Phys. Lett. 2001, 78 (15), 2214-2216. (c) Dai, H. J. Acc. Chem. Res. 2002, 35 (12), 1035-1044. (d) Li, Y. M.; Kim, W.; Zhang, Y. G.; Rolandi, M.; Wang, D. W.; Dai, H. J. J. Phys. Chem. B 2001, 105 (46), 11424-11431. (e) Nasibulin, A. G.; Pikhitsa, P. V.; Jiang, H.; Kauppinen, E. I. Carbon 2005, 43 (11), 2251-2257.

(11) (a) Lolli, G.; Zhang, L. A.; Balzano, L.; Sakulchaicharoen, N.; Tan, Y. Q.; Resasco, D. E. J. Phys. Chem. B 2006, 110 (5), 2108-2115. (b) Wu, Y.; Cui, Y.; Huynh, L.; Barrelet, C. J.; Bell, D. C.; Lieber, C. M. Nano Lett. 2004, 4 (3), 433-436.

(12) Amikura, K.; Kimura, T.; Hamada, M.; Yokoyama, N.; Miyazaki, J.; Yamada, Y. Appl. Surf. Sci. 2008, 254 (21), 6976-6982.

(13) Piner, R. D.; Zhu, J.; Xu, F.; Hong, S. H.; Mirkin, C. A. Science 1999, 283 (5402), 661-663.

(14) Wallraff, G. M.; Hinsberg, W. D. Chem. Rev. 1999, 99 (7), 18011821.

(15) (a) Blake, A. J.; Champness, N. R.; Hubberstey, P.; Li, W. S.; Withersby, M. A.; Schroder, M. Coord. Chem. Rev. 1999, 183, 117-138. (b) Lu, J.; Yi, S. S.; Kopley, T.; Qian, C.; Liu, J.; Gulari, E. J. Phys. Chem. B 2006, 110 (13), 66556660. (c) Lu, J. Q.; Kopley, T. E.; Moll, N.; Roitman, D.; Chamberlin, D.; Fu, Q.; Liu, J.; Russell, T. P.; Rider, D. A.; Manners, I.; Winnik, M. A. Chem. Mater. 2005, 17 (9), 2227. (d) Son, S. U.; Park, I. K.; Park, J.; Hyeon, T. Chem. Commun. 2004, (7), 778-779. (e) Spatz, J. P.; Mossmer, S.; Hartmann, C.; Moller, M.; Herzog, T.; Krieger, M.; Boyen, H. G.; Ziemann, P.; Kabius, B. Langmuir 2000, 16 (2), $407-415$.

(16) Sillen, L. G. M.; A. E.; Njerrum, J. In Stability Constants of MetalIon Complexes; New York Peragamon Press: Oxford, pp 1979-1982.

(17) Wagner, C. D. N., A.; Kraut-Vass, A.; Allison, J. W.; Powell, C. J.; Rumble, J. R. J. NIST X-ray Photoelectron Spectroscopy Database, Version, 3.4, 2003.

JP9099545 